\title{
COMPARATIVE STUDY OF DILTIAZEM VERSUS LIGNOCAINE FOR ATTENUATION OF PRESSOR RESPONSE DURING LARYNGOSCOPY AND ENDOTRACHEAL INTUBATION
}

\author{
Nimisha Mahesh Parkar1, Sharmila Borkar ${ }^{2}$
}

1 Senior Resident, Department of Anaesthesiology, Goa Medical College, Bambolim, Goa, India.

${ }^{2}$ Associate Professor, Department of Anaesthesiology, Goa Medical College, Bambolim, Goa, India.

\section{BACKGROUND}

ABSTRACT

Tachycardia and systolic hypertension are considered the usual circulatory responses to laryngoscopy and tracheal intubation, occurring by virtue of sympathetic response, ${ }^{1,2}$ accompanied by catecholamine activity. ${ }^{3}$ Hence, suppression of this response is beneficial.

The aim of this study was to compare the efficacy of Intravenous Diltiazem in two different doses with intravenous Lignocaine in attenuating the haemodynamic responses to endotracheal intubation.

\section{MATERIALS AND METHODS}

Ninety patients belonging to American Society of Anesthesiologists (ASA) class I and II, normotensive, in the age group of 18 - 60 years, who were scheduled for various elective surgical procedures, were included in the study and randomly allocated into 3 groups of 30 patients each; Group I received Diltiazem $(0.1 \mathrm{mg} / \mathrm{kg})$, Group II received Diltiazem $(0.2 \mathrm{mg} / \mathrm{kg})$ and Group III received Lignocaine (1.5 mg/kg), 90 seconds preceding laryngoscopy and intubation. Heart rate, systolic and diastolic blood pressure, mean arterial pressure and rate pressure product were recorded at different intervals.

Statistical Analysis was performed using ANOVA (Analysis of Variance) with repeated measures for comparison of above variables within and between groups for p-value.

Setting and Design- The present prospective, randomised, double-blind, controlled clinical study was carried out in a tertiary care teaching hospital.

\section{RESULTS}

Greatest attenuation of measured parameters measured after laryngoscopy namely heart rate, systolic and diastolic pressures and mean arterial pressures was seen in Group 2 (Diltiazem $0.2 \mathrm{mg} / \mathrm{kg}$ ) and as a result comparatively lower rate pressure product at 1 , 3,5 and 10 minutes post intubation providing greater cardio protective effect during laryngoscopy and endotracheal intubation.

\section{CONCLUSION}

The Diltiazem in a dose of $0.2 \mathrm{mg} / \mathrm{kg}$ showed superior attenuation than Diltiazem administered in a dose of $0.1 \mathrm{mg} / \mathrm{kg}$ and Lignocaine in a dose of $1.5 \mathrm{mg} / \mathrm{kg}$. The study establishes that the haemodynamic outcomes of laryngoscopy and tracheal intubation are short lasting and soon normalcy returns.

\section{KEY WORDS}

Diltiazem, Haemodynamic Stress Response, Intubation, Laryngoscopy, Lignocaine.

HOW TO CITE THIS ARTICLE: Parkar NM, Borkar S. Comparative study of diltiazem versus lignocaine for attenuation of pressor response during laryngoscopy and endotracheal intubation. J. Evolution Med. Dent. Sci. 2018;7(26):2982-2988, DOI: $10.14260 /$ jemds/2018/672

\section{BACKGROUND}

Sympathetic response ${ }^{1,2}$ accompanied by catecholamine activity $^{3}$ is often a consequence of laryngoscopy and placement of tracheal tube manifesting as tachycardia and systolic hypertension. Being transient is of no significant consequences in healthy individuals, but may result in hazardous outcomes in those with cardiovascular and cerebrovascular diseases. $4,5,6$

Several recommendations for attenuation of pressor response evoked by upper airway irritation including curtailing the duration of laryngoscopy, laryngo-tracheal instillation of Lignocaine, blocking the efferent pathway along

'Financial or Other Competing Interest': None.

Submission 14-05-2018, Peer Review 08-06-2018,

Acceptance 14-06-2018, Published 25-06-2018.

Corresponding Author:

Nimisha Mahesh Parkar,

Tukaram Krupa,

Thal Shiroda-403103, Goa, India.

E-mail: nimishaparker@gmail.com

DOI: $10.14260 /$ jemds $/ 2018 / 672$

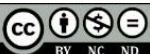

with the efferent site by intravenous Lignocaine, adrenergic blocking drugs and intravenous anaesthetic inducing agents.

Besides minimising the cardiovascular response, the agents should prevent impairment of cerebral blood flow, avoid arousal of the patient without being time-consuming and without altering the duration or modality of the ensuing anaesthesia ${ }^{7}$ and not affect recovery.

Recent several studies have pointed the efficiency of Calcium channel blockers like Diltiazem by virtue of their properties, direct vasodilation and negative chronotropic and dromotropic effects. $8,9,10$ Therefore, comparison of the effects of intravenous Diltiazem and intravenous Lignocaine, a more commonly used agent, on blunting the pressor responses to endotracheal intubation was done in our study.

\section{MATERIALS AND METHODS}

The prospective, randomised, double-blind, controlled clinical study was conducted over a period of 15 months, on procuring ethical committee clearance and informed consent from all patients. Ninety patients scheduled for various elective surgical procedures belonging to American Society of 
Anesthesiologists (ASA) class I and II, normotensive were included in the study, belonging to the age group of $18-60$ years.

\section{Patients were Randomly Allocated into 3 Groups- Inclusion Criteria for the Study}

1. Adult patients aged between 18 and 60 years of both sex.

2. Patients belonging to ASA class I and II.

3. Patients having airway Mallampati grade I and II.

4. Patients undergoing elective surgeries under general anaesthesia with oral endotracheal intubation.

\section{Exclusion Criteria for the Study}

1. Cardiovascular disease, respiratory conditions, hepatic and renal dysfunction, cerebrovascular insufficiency, peripheral vascular disease.

2. Patient with hypertension.

3. $\mathrm{BMI}>30$.

4. Anticipated difficult airway.

5. Pregnancy/ Lactation, Opium addiction.

6. 1st, 2nd or 3rd degree heart block.

7. Patients with heart rate less than 60 beats per minute, systolic blood pressure less than $100 \mathrm{mmHg}$ at the time of pre-anaesthetic check-up.

Drug under study Diltiazem was used in 2 doses, 0.1 $\mathrm{mg} / \mathrm{kg}$ and $0.2 \mathrm{mg} / \mathrm{kg}$. The efficacy of this drug in two separate doses was compared with Lignocaine $(1.5 \mathrm{mg} / \mathrm{kg})$. We also studied the safety of the two drugs used for the same purpose.

As advised by statistician, a pilot study was conducted. We used the mean heart rate at 5 mins in three groups to estimate the sample size at the end of pilot study. At $95 \%$ confidence limit and $90 \%$ power, estimated sample size of 26 was deduced in each group by taking largest mean difference of 7.91 and expected background standard deviation (SD) of 9.1. With $10 \%$ dropouts, sample size of $26+2.6,30$ participants were included in the study in each group.

Group I $(\mathrm{n}=30)$ received $0.1 \mathrm{mg} / \mathrm{kg}$ of intravenous Diltiazem, 90 seconds prior to laryngoscopy and intubation.

Group II $(\mathrm{n}=30)$ received $0.2 \mathrm{mg} / \mathrm{kg}$ of intravenous Diltiazem 90 seconds prior to laryngoscopy and intubation.

Group III $(\mathrm{n}=30)$ received $1.5 \mathrm{mg} / \mathrm{kg}$ of intravenous Lignocaine (2\%) 90 seconds prior to laryngoscopy and intubation.

All the study patients were subjected to a routine preanaesthetic check-up, kept nil per oral overnight. On the arrival to the operating room, an 18-gauge/20-gauge intravenous cannula was inserted and an infusion of Ringer Lactate was started at $4 \mathrm{~mL} / \mathrm{kg} /$ hour. The patients were connected to multi-channel monitor which displayed heart rate, non-invasive blood pressure (NIBP), end tidal carbon dioxide concentration, continuous ECG monitoring and oxygen saturation.

The baseline blood pressure and heart rate were recorded from the same non-invasive monitor and cardiac rate and rhythm were also monitored from a continuous display of electrocardiogram from lead II. Inj. Midazolam 0.02 $\mathrm{mg} / \mathrm{kg} \mathrm{IV}$ and Inj. Ondansetron $4 \mathrm{mg}$ IV was given to all the patients before induction as a premedication. Atropine or Glycopyrrolate as a pre-medication was avoided during the brief study period, i.e. until 10 minutes post laryngoscopy as they cause tachycardia which is attributed to their vagolytic property and not attributable to sympathetic stimulation. However, IV Glycopyrrolate $0.2 \mathrm{mg}$ was administered at the end of study period upon recording the parameters under study.

To eliminate bias "two operator" technique was employed and the cases were randomly allocated, sealed envelope containing computer generated random number corresponding to one of the three groups. This was done by investigator selected to prepare the study drug solutions and further monitoring was done by an investigator blinded to group allocated.

The study drug was prepared by senior anaesthesiologist, who was not involved in the study. The observer as well as the patient was blinded for the study. The patients were preoxygenated with $100 \%$ oxygen for three minutes with a face mask using a closed circuit. General anaesthesia was induced with intravenous Thiopentone sodium $5-7 \mathrm{mg} / \mathrm{kg}, 2.5 \%$ solution, till loss of eyelash reflex was noted. Intravenous Vecuronium $0.1 \mathrm{mg} / \mathrm{kg}$ was used to achieve muscle relaxation after confirming mask ventilation. Thiopentone is more cardio stable and leads to minimal alteration in haemodynamic parameters as compared to Propofol. Nondepolarising neuromuscular blocker chosen was Vecuronium, a steroidal compound, having minimal cardiovascular adverse effects and lacking histamine releasing property.

The test drug which was administered as a slow IV bolus, 90 seconds prior to laryngoscopy and intubation which was done using Macintosh blade. The patients were intubated with appropriate sized cuffed endotracheal tubes. Laryngoscopy was performed by experienced anaesthesiologist of minimum 3 years' experience. All due measures were taken, so that the laryngoscopy lasted for less than 15 seconds. Patients were excluded from the study if time for laryngoscopy and intubation exceeded 15 seconds and in whom more than one attempt was required. The endotracheal tube was fixed only after confirming bilateral equal air entry.

In order to gain adequate depth of anaesthesia, Sevoflurane (1\%) and Nitrous oxide with Oxygen (66\%: 33\%) were initiated and continued till the end of the study period. For the next 10 minutes of study period, no surgical or any other stimulus was applied until 10 minutes after intubation. After study period of 10 minutes, IV Fentanyl ( $2 \mu \mathrm{g} / \mathrm{kg}$ ) and IV Glycopyrrolate $0.2 \mathrm{mg}$ were administered. Opioids such as Fentanyl obtund the sympathetic response to laryngoscopy and endotracheal intubation in a dose dependent manner (2$20 \mu \mathrm{g} / \mathrm{kg})^{11}$ and they are commonly used as adjuvant to inhalational agent for the same purpose. However, in the present study aiming at reviewing the properties of Calcium channel blocker (Diltiazem) and $\mathrm{Na}$ channel inhibitor (Lignocaine) for this purpose, i.e. as agents to suppress this circulatory reflex, it was decided not to administer Fentanyl in addition to study drug at induction as it would interfere with interpretation of the results and inability to attribute the outcome to a single agent. However, following the study period of 10 minutes post laryngoscopy, titrated doses of IV Fentanyl were administered in order to provide intraoperative analgesia. Neuromuscular blockade was maintained with $0.06 \mathrm{mg} / \mathrm{kg}$ Vecuronium bromide. Anaesthesia was reversed with IV Neostigmine $0.05 \mathrm{mg} / \mathrm{kg}$ and IV Glycopyrrolate $0.01 \mathrm{mg} / \mathrm{kg}$ bolus. 
The patients were extubated once they were fully awake and on confirming satisfactory respiratory efforts.

Observations were noted on the proforma from automatic monitors by person, who administered the drug and who was blinded.

It is noteworthy that Sevoflurane and Nitrous oxide depress arterial baroreceptor reflex function. However, this practice was undertaken for all cases in order to standardise the result. Nitrous oxide provides a prominent, but a short lived analgesic effect for 20 minutes. ${ }^{12}$ Sevoflurane causes tachycardia only at a higher MAC ( $>1.5),{ }^{13}$ hence it does not bias the results pertaining to heart rate.

\section{All the Cardiovascular Parameters of the Study were} recorded at Following Stages-

- Preoperative.

- After giving the study drug.

- Immediately after intubation.

- At 1 minute, 3 minutes and 5 minutes, 10 minutes after laryngoscopy and intubation.

\section{The Cardiovascular Parameters Measured Were-}

- Heart rate (HR)- beats per minute.

- $\quad$ Systolic blood pressure (SBP)- mmHg.

- $\quad$ Diastolic blood pressure (DBP)- mmHg.

- Mean arterial pressure (MAP)- mmHg.

Mean arterial pressure $=$ Pulse pressure $+(1 / 3 \mathrm{x}$ Diastolic BP). Rate pressure product $=$ Heart rate $\mathrm{x}$ Systolic BP.

Adverse effects if any were noted. Hypotension was treated with IV fluids or IV Ephedrine $6 \mathrm{mg}$. Bradycardia was treated with IV Glycopyrrolate $0.2 \mathrm{mg}$.

On an average, the duration of each of these procedures did not exceed the half-life of the drugs under study. The haemodynamic monitoring of study subjects was undertaken intra- and post-operatively in the recovery period.

\section{Statistical Methods}

The data obtained in the study are presented in tabulated manner and variables are expressed as Mean \pm SD. Categorical data was compared using Chi-square test. Numerical data was compared using one-way ANOVA for multiple comparison.

p-value $<0.05$ was considered as significant.

\section{Repeated Measure ANOVA}

Repeated measures analyses groups of related dependent variables that represent different measurements of the same attribute. This dialog box lets us define one or more within subject factors for use in GLM Repeated Measures. The order in which you specify within subject factors is important. Each factor constitutes a level within the previous factor. Analysis of data was undertaken using SPSS (version 17.0). Data was summarised as numbers, percentage, mean and standard deviation (SD).
$\mathrm{P}<0.05$ was considered to be significant, whereas $\mathrm{p}>0.05$ was regarded as not significant.

\section{RESULTS}

\begin{tabular}{|c|c|c|c|c|}
\hline & Group 1 & Group 2 & Group 3 & P value \\
\hline Age & $35.13 \pm 8.37$ & $37.90 \pm 13.13$ & $35.23 \pm 13.02$ & $>0.05$ \\
\hline Weight & $62.8 \pm 10.10$ & $60.07 \pm 10.41$ & $58.70 \pm 9.15$ & $>0.05$ \\
\hline Sex & $14 / 16$ & $13 / 17$ & $16 / 14$ & $>0.05$ \\
\hline ASA I/II & $22 / 8$ & $20 / 10$ & $20 / 10$ & $>0.05$ \\
\hline $\begin{array}{l}\text { Height } \\
\text { (cms) }\end{array}$ & $161.3 \pm 6.87$ & $162.6 \pm 7.12$ & $161.9 \pm 6.36$ & $>0.05$ \\
\hline \multicolumn{5}{|c|}{$\begin{array}{c}\text { Table 1. Demographic Data of the patients in the Three } \\
\text { Groups }\end{array}$} \\
\hline
\end{tabular}

The demographic data did not differ among the three groups studied.

\section{Comparison of Heart Rate}

\begin{tabular}{|c|c|c|c|c|}
\hline Time & Group 1 & Group 2 & Group 3 & p value \\
\hline B & $86.00 \pm 10.18$ & $86.83 \pm 15.82$ & $85.27 \pm 12.02$ & .240 \\
\hline D & $91.30 \pm 9.71$ & $90.00 \pm 15.72$ & $92.13 \pm 12.08$ & .060 \\
\hline I & $98.10 \pm 9.56$ & $94.33 \pm 16.10$ & $99.30 \pm 11.97$ & $<0.05$ \\
\hline I-1 & $94.97 \pm 9.53$ & $90.90 \pm 15.88$ & $97.27 \pm 12.01$ & $<0.05$ \\
\hline I-3 & $91.93 \pm 9.62$ & $85.90 \pm 15.92$ & $94.90 \pm 11.37$ & $<0.05$ \\
\hline I-5 & $87.77 \pm 9.63$ & $80.03 \pm 15.75$ & $91.87 \pm 11.56$ & $<0.05$ \\
\hline I-10 & $81.17 \pm 17.90$ & $74.27 \pm 15.40$ & $88.43 \pm 11.36$ & $<0.05$ \\
\hline \multicolumn{5}{|c|}{ Table 2. Intergroup Comparison of Heart } \\
Rates at various Time Intervals \\
\hline
\end{tabular}

Statistical evaluation between groups showed a significant rise in heart rate at the time of drug administration and intubation compared to baseline. In intergroup comparison, Group 2 had a significantly lower heart rate followed by Group 1 as compared to Group 3 $(\mathrm{p}<0.05)$. Subsequently there is a fall in heart rate at $1,3,5$ and 10 minutes following intubation. This fall in mean heart rates was comparable between the three groups and was of statistical significance $(\mathrm{p}<0.05)$.

\section{Comparison of Mean Systolic Blood Pressure}

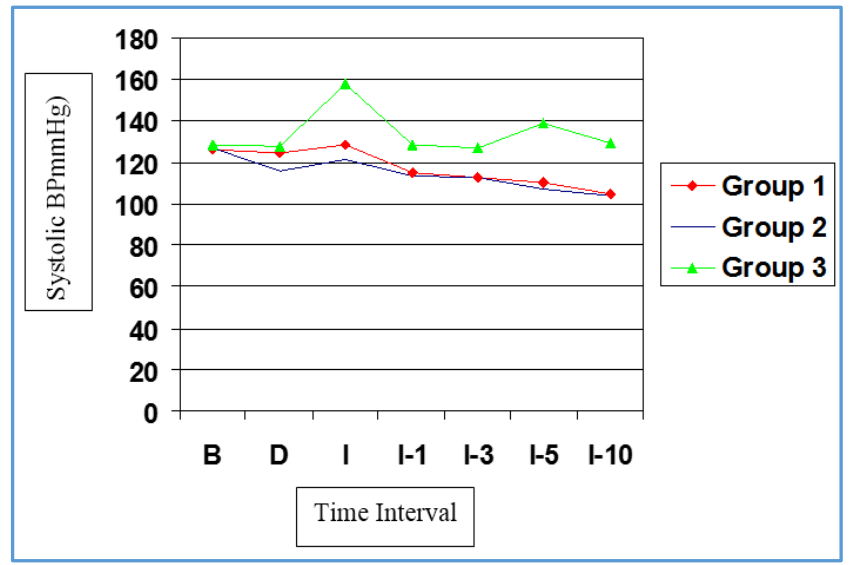

Figure 1. Comparison of Mean Systolic Blood Pressure at various Time Intervals 


\begin{tabular}{|c|c|c|c|c|}
\hline Time & Group 1 & Group 2 & Group 3 & P value \\
\hline B & $125.93 \pm 12.4$ & $127.20 \pm 13.6$ & $128.56 \pm 5.99$ & 0.662 \\
\hline D & $124.66 \pm 13.7$ & $115.70 \pm 10.06$ & $127.80 \pm 5.82$ & 0.000 \\
\hline I & $\begin{array}{c}128.70 \pm \\
12.54\end{array}$ & $121.20 \pm 18.5$ & $157.86 \pm 4.88$ & 0.000 \\
\hline I-1 & $114.6 \pm 12.09$ & $113.0 \pm 11.17$ & $128.33 \pm 5.21$ & 0.000 \\
\hline I-3 & $112.56 \pm 12.3$ & $112.80 \pm 10.45$ & $127.10 \pm 5.36$ & 0.000 \\
\hline I-5 & $\begin{array}{c}110.16 \pm \\
15.09\end{array}$ & $107.43 \pm 13.4$ & $139.03 \pm 8.11$ & 0.000 \\
\hline I-10 & $\begin{array}{c}104.86 \pm \\
13.15\end{array}$ & $103.70 . \pm 11.5$ & $129.20 \pm 7.11$ & 0.000 \\
\hline
\end{tabular}

Table 3. Intergroup comparison of Systolic Blood Pressure

Evaluation between groups showed that alterations in SBP at the time of intubation compared to baseline were noted, Group 2 showing a mean fall and Group 1 and 3 showing a rise in SBP. These changes being of significance $(\mathrm{p}<0.05)$. Subsequently, there is a fall in SBP at 1, 3, 5 and 10 minutes following intubation. This fall in mean SBP was comparable between the three groups and was of statistical significance $(\mathrm{p}<0.05)$.

From the above table it is seen that Diltiazem blunts the increase in systolic blood pressure, more pronounced at a dose of $0.2 \mathrm{mg} / \mathrm{kg}$ than $0.1 \mathrm{mg} / \mathrm{kg}$.

\section{Comparison of Diastolic Blood Pressure}

\begin{tabular}{|c|c|c|c|c|}
\hline Time & Group 1 & Group 2 & Group 3 & P value \\
\hline B & $79.03 \pm 9.56$ & $79.50 \pm 9.40$ & $77.40 \pm 2.44$ & 0.722 \\
\hline D & $77.10 \pm 8.19$ & $72.03 \pm 10.41$ & $75.73 \pm 5.00$ & 0.051 \\
\hline I & $87.96 \pm 14.32$ & $84.36 \pm 13.36$ & $98.73 \pm 5.97$ & 0.000 \\
\hline I-1 & $70.60 \pm 11.82$ & $67.73 \pm 14.37$ & $85.86 \pm 8.21$ & 0.000 \\
\hline I-3 & $68.73 \pm 8.75$ & $70.63 \pm 11.08$ & $76.13 \pm 5.32$ & 0.004 \\
\hline I-5 & $70.60 \pm 11.82$ & $67.73 \pm 14.37$ & $85.86 \pm 8.21$ & 0.000 \\
\hline I-10 & $68.63 . \pm 10.59$ & $65.16 \pm 12.89$ & $80.53 \pm 7.61$ & 0.000 \\
\hline \multicolumn{5}{|c|}{ Table 4. Intergroup comparison of Diastolic Blood } \\
Pressure \\
\hline
\end{tabular}

The basal mean DBP were comparable in all three groups. Statistical evaluation between the groups showed a significant fall in DBP in all 3 groups post intubation. The decrease in mean DBP observed at 1st, 5th and 10th minutes after intubation in Group 2 and Group 1 was statistically highly significant compared to same in Group $3(p=0.000)$.

\section{Comparison of Mean Arterial Pressure}

\begin{tabular}{|c|c|c|c|c|}
\hline Time & Group 1 & Group 2 & Group 3 & P value \\
\hline B & $93.40 \pm 6.93$ & $94.73 \pm 11.53$ & $92.00 \pm 3.17$ & 0.419 \\
\hline D & $90.70 \pm 6.48$ & $85.9 \pm 9.55$ & $91.26 \pm 4.11$ & 0.007 \\
\hline I & $102.10 \pm 12.7$ & $94.93 \pm 14.19$ & $117.6 \pm 5.81$ & 0.000 \\
\hline I-1 & $86.00 \pm 6.83$ & $85.00 \pm 11.98$ & $91.13 \pm 3.40$ & 0.010 \\
\hline I-3 & $82.80 \pm 8.40$ & $82.50 \pm 11.49$ & $91.20 \pm 3.96$ & 0.001 \\
\hline I-5 & $82.10 \pm 10.11$ & $82.30 \pm 15.5$ & $\begin{array}{c}102.83 \pm \\
7.59\end{array}$ & 0.000 \\
\hline I-10 & $79.66 . \pm 9.63$ & $79.40 \pm 13.26$ & $96.56 \pm 6.59$ & 0.000 \\
\hline Table 5. Intergroup comparison of Mean Arterial Pressure \\
\hline
\end{tabular}

Statistical evaluation between groups showed that changes in MAP after drug administration and intubation were statistically significant. Subsequently, there was a fall in MAP at 1, 3, 5 and 10 minutes following intubation. This fall in mean arterial pressure was comparable between the three groups and was of statistical significance $(p<0.05)$ except at 1-minute post intubation.

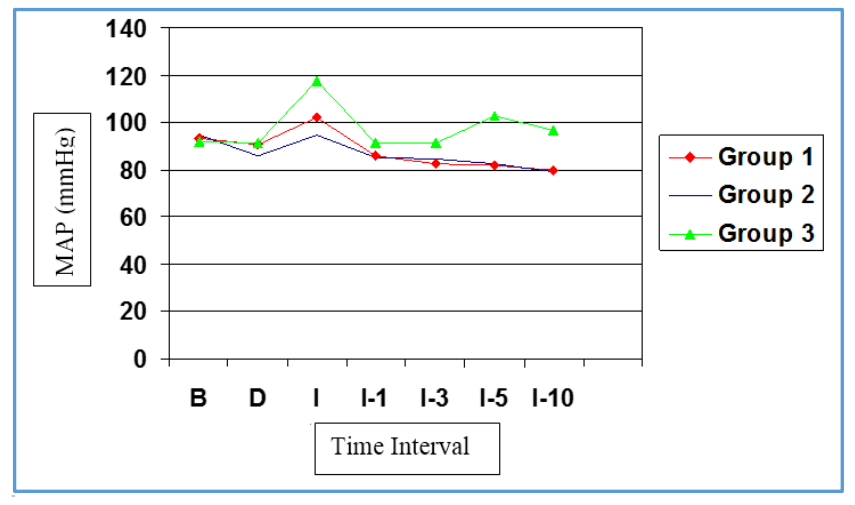

Figure 2. Comparison of Mean Arterial Pressure at various Time Intervals

Comparison of Rate Pressure Product

\begin{tabular}{|c|c|c|c|c|}
\hline Time & Group 1 & Group 2 & Group 3 & P value \\
\hline B & $10829.98 \pm 20$ & $11044.78 \pm 49$ & $\begin{array}{c}10962.31 \pm \\
13\end{array}$ & 0.642 \\
\hline D & $11381.46 \pm 74$ & $10413.00 \pm 72$ & $\begin{array}{c}11774.21 \pm \\
27\end{array}$ & 0.000 \\
\hline I & $12625.47 \pm 22$ & $11432.80 \pm 45$ & $\begin{array}{c}15675.50 \pm \\
01\end{array}$ & 0.000 \\
\hline I-1 & $10883.56 \pm 12$ & $10271.70 \pm 50$ & $\begin{array}{c}12482.66 \pm \\
61\end{array}$ & 0.000 \\
\hline I-3 & $10347.64 \pm 02$ & $9689.52 \pm 24$ & $\begin{array}{c}12061.79 \pm \\
80\end{array}$ & 0.000 \\
\hline I-5 & $9668.74 \pm 34$ & $8597.62 \pm 17$ & $\begin{array}{c}12772.69 \pm \\
32\end{array}$ & 0.000 \\
\hline I-10 & $8511.48 \pm 45$ & $7701.79 \pm 03$ & $\begin{array}{c}11425.16 \pm \\
92\end{array}$ & 0.000 \\
\hline
\end{tabular}

Table 6. Intergroup comparison of Rate Pressure Product

\section{Adverse Effects}

- Bradycardia (Pulse rate less than 60 beats/minute).

- Hypotension (Decrease in systolic BP of more than $30 \%$ compared to baseline level).

- Dysrhythmias (Ventricular or Supraventricular premature beat or any rhythm other than sinus).

- Bradycardia and hypotension.

\begin{tabular}{|c|c|c|c|}
\hline Adverse Effect & Group 1 & Group 2 & Group 3 \\
\hline Bradycardia & 1 & 3 & 0 \\
\hline Hypotension & 1 & 4 & 2 \\
\hline Dysrhythmias & 0 & 0 & 0 \\
\hline Bronchospasm & 0 & 0 & 0 \\
\hline \multicolumn{3}{|c|}{ Table 7. Adverse Effects } \\
\hline
\end{tabular}

\section{DISCUSSION}

Surgical procedures conducted routinely or on emergency basis necessitate the administration of general anaesthesia with endotracheal intubation. The most crucial event during this process is the conduct of laryngoscopy that initiates a transient, but discernible sympathetic reaction ${ }^{14,15}$ in the form of tachycardia and hypertension. ${ }^{4}$

Cardiovascular complications are one of the frequently encountered causes of anaesthesia-related morbidity. 16

The postulated mechanisms for alterations in the haemodynamics are narrowing of arterial lumen, suppression of baroreceptor reflex and increased sympathetic activity. ${ }^{4,17,18}$

The need for suppression of haemodynamic response arises in candidates with cardiovascular jeopardy such as 
hypertension, ischaemic heart disease and cerebrovascular conditions, ${ }^{19}$ most notably being intracranial aneurysms, pulmonary oedema, left ventricular failure, myocardial ischaemia, ${ }^{20}$ ventricular dysrhythmia and cerebral haemorrhage.

Lignocaine attenuates sympathetic response to laryngoscopy and intubation by one or combination of following mechanisms-

1. It inhibits influx of sodium in the voltage gated sodium channels in the neuronal cell membrane blocking transmission of impulses. ${ }^{14}$

2. Reduction in the sensitivity of cardiac muscles to electrical impulses, which retards conduction of signals enables restoration of a regular cardiac rhythm. ${ }^{21}$

3. Direct cardiac depression and peripheral vasodilatation. 19,22

Lignocaine has been used for blunting of pressor responses to intubation since a long time, ${ }^{23}$ especially due to its capability to suppress airway reflexes triggered by tracheal mucosal irritation and its analgesic as well as antiarrhythmic properties. ${ }^{15,23}$ Intravenous (IV) Lignocaine is one of the oldest, cheapest and most easily available drug used for suppression of haemodynamic response to laryngoscopy and intubation. $24,25,26,27,28,12$

However, few studies 28,29 reported that the Lignocaine failed to attenuate haemodynamic response effectively.

\section{Diltiazem attenuates the Cardiovascular Response to Intubation by the following Actions-}

- Blockade of voltage sensitive L type channels and inhibition of calcium entry mediated action potential in smooth and cardiac muscle cell.

- Control of hypertension by virtue of its peripheral vasodilating action ${ }^{19}$ and facilitating evident reduction in blood pressure.

- Prevention or blockade of the release of catecholamines, which reduce sympathetic nervous system activity.

- Slowing of conduction of normal electrical impulse through the AV node with consequent increase in the time needed for each beat, eventually resulting in reduced myocardial oxygen consumption.

\section{Doses of Study Drugs}

\section{Dose of Lignocaine}

The dose of IV Lignocaine $1.5 \mathrm{mg} / \mathrm{kg}$ was selected, as it has been recommended to be most appropriate dose and time 90 seconds prior to laryngoscopy was selected as supported by Dahlgren et al, Denlinger et al and Stoelting. 30,31,32

Several authors $27,28,33$ have inferred and recommended that $1.5 \mathrm{mg} / \mathrm{kg}$ of Lignocaine suppresses stress response to intubation.

\section{Dose for Diltiazem}

Therapeutic dose of Diltiazem is $0.03-0.3 \mathrm{mg} / \mathrm{kg}$. Mohan K et $\mathrm{al}^{34}$ concluded from their study that Diltiazem $0.2 \mathrm{mg} / \mathrm{kg}$ is reliably efficient in controlling the heart rate response to tracheal intubation.

Mikawa $\mathrm{K}$ et $\mathrm{al}^{8}$ suggested that administration of 0.3 $\mathrm{mg} / \mathrm{kg}$ Diltiazem had a greater inhibitory effect on the increase in blood pressure associated with intubation than did $0.2 \mathrm{mg} / \mathrm{kg}$. They concluded that Diltiazem $0.3 \mathrm{mg} / \mathrm{kg}$ was better able to attenuate the haemodynamic response i.e. heart rate, systolic blood pressure, diastolic blood pressure and mean arterial pressure associated with laryngoscopy and intubation without any adverse effects. Although, in their previous report Mikawa $\mathrm{K}$ et al ${ }^{8}$ recommended a dose of 0.3 $\mathrm{mg} / \mathrm{kg}$ of Diltiazem, their preliminary study cases led to severe hypotension in 2 out of 5 patients with systolic blood pressure less than $75 \mathrm{mmHg}$. Hence, in the current study, maximum dose of $0.2 \mathrm{mg} / \mathrm{kg}$ was chosen and $0.1 \mathrm{mg} / \mathrm{kg}$ dose was used for comparative purpose for the same drug.

Manjunath et al ${ }^{35}$ suggested Diltiazem in the dose of $0.2 \mathrm{mg} / \mathrm{kg}$ could be used to blunt pressor responses (though to lesser extent than the combination of Lignocaine and Diltiazem) as compared to other studies where $0.3 \mathrm{mg} / \mathrm{kg}$ has been used.

Diltiazem $0.2 \mathrm{mg} / \mathrm{kg}$ definitely has a cardio protective action and can be safely used in high-risk patients who have hypertension and ischaemic heart disease with low ejection fraction.

\section{Time of Administration of Drugs}

In the current study, the drugs Diltiazem in 2 separate doses and Lignocaine were both administered 90 seconds prior to laryngoscopy and endotracheal intubation.

Calcium blockers can be best administered when their peak effects correspond to the onset and peak pressor responses. It has been reported before that MAP begins to increase about 15 seconds after laryngoscopy and reaches peak value at around 45 seconds, if no agent to suppress pressor response is administered to patients. ${ }^{36}$

However, being a double-blind study, time of administration of the unknown test drug was fixed and kept constant irrespective of the study group in order to avoid bias in the recording and interpretation of results. Also, onset of antihypertensive action of Diltiazem $(0.2 \mathrm{mg} / \mathrm{kg})$ occurs within approximately 30 seconds after a single IV injection with a peak effect occurring at 1.5 - 2 minutes.

Manjunath et al ${ }^{35}$ found Diltiazem $0.2 \mathrm{mg} / \mathrm{kg}$ one minute before laryngoscopy and intubation blunts unwanted haemodynamic responses in normotensive patients.

Goel S et al ${ }^{37}$ administered Diltiazem $(0.3 \mathrm{mg} / \mathrm{kg})$ and Lignocaine $(1.5 \mathrm{mg} / \mathrm{kg}) 90$ seconds prior to laryngoscopy in their study.

Our study involving normotensive patients exhibited some similarities and differences in terms of HR, SBP, DBP, MAP and RPP values immediately after tracheal intubation with respect to studies priorly conducted.

Comparative Analysis of Changes in Haemodynamics at various Time Intervals between Diltiazem $(0.1 \mathrm{mg} / \mathrm{kg})$, Diltiazem $(0.2 \mathrm{mg} / \mathrm{kg})$ and Lignocaine $(1.5 \mathrm{mg} / \mathrm{kg})$

In our study, maximum increase in heart rate occurred at 1 immediately following laryngoscopy and intubation in all 3 groups. It was $14.06 \%$ from baseline value in Group 1, 8.63\% increase was noted in Group 2 and in Lignocaine group it was $16.45 \%$ from the baseline value. At 3 and 5 minutes, the heart rate response to laryngoscopy and intubation in both the Diltiazem groups was clinically lesser compared to Lignocaine group and statistically highly significant $(\mathrm{p}<0.001)$. Around the 10 th minute, all 3 groups showed a mean heart rate close to their baseline values.

Santosh SK et al ${ }^{10}$ observed a rise in heart rate after 
intubation following Diltiazem administration which was significant statistically, also co-relating with findings suggested by Mikawa et al. ${ }^{8}$ The same study postulated that it was a reflex sympathetic stimulation, which caused this rise in heart rate.

Attenuation of systolic blood pressure by Diltiazem group 2 was statistically significant at 1, 3 and 5 which was better compared to Group 1 and the Lignocaine group. Diltiazem $(0.2 \mathrm{mg} / \mathrm{kg})$ attenuates the rise in systolic blood pressure due to laryngoscopy and intubation better than Lignocaine in our study.

In the study by Singh $\mathrm{S}$ et al ${ }^{38}$ with Diltiazem $0.2 \mathrm{mg} / \mathrm{kg}$ change in mean SBP at 1 minute was $9.64 \%$, less than that occurring with Lignocaine administration (11.84\%).

We concluded that Diltiazem blunts the increase in mean diastolic blood pressure and it was more pronounced at a dose of $0.2 \mathrm{mg} / \mathrm{kg}$ than $0.1 \mathrm{mg} / \mathrm{kg}$. This blunting response is greater than that reflected in the results following usage of Lignocaine.

Manjunath et al ${ }^{35}$ suggested Lignocaine attenuated DBP at all points of time with $8 \%$ fall in the value at minutes (Comparable with $8.71 \%$ fall observed in the current study results).

Similarly, when mean arterial pressures were compared, both Diltiazem group showed statistically highly significant attenuation of mean arterial pressure than the Lignocaine group at 1, 3, 5 and 10 minutes from the onset of laryngoscopy, more so in Diltiazem in higher dose. Changes in mean arterial pressure were noted to be consistent with those stated in the study by Santosh SK et al ${ }^{10}$ and Bukhari ST et al $^{39}$ with respect to Diltiazem and Lignocaine.

Rate pressure product is defined as a product of pulse rate and peak systolic blood pressure and it is strongly linked to myocardial blood flow, myocardial oxygen consumption and thus can signify ischaemia. 40 In the current study, IV Diltiazem in the dose of $0.2 \mathrm{mg} / \mathrm{kg}$ showed progressive decrease in RPP following intubation as compared to lower dose of Diltiazem. Lignocaine showed changes comparable with the lower dose of Diltiazem, i.e. increase in RPP till 1 minute post intubation followed by a progressive fall from baseline. The RPP levels close to 20,000 show an association with angina and myocardial ischaemia. $35,40,41$ RPP at 1 min after intubation remained less than 20,000 in study drug groups. These findings confirm the cardio protective effect of study drugs during laryngoscopy and endotracheal intubation.

\section{CONCLUSION}

Diltiazem in a dose of $0.2 \mathrm{mg} / \mathrm{kg}$ showed superior attenuation than Diltiazem administered in a dose of $0.1 \mathrm{mg} / \mathrm{kg}$ and Lignocaine given in a dose of $1.5 \mathrm{mg} / \mathrm{kg}$. The study establishes that the haemodynamic outcomes of laryngoscopy and tracheal intubation are short lasting and soon normalcy returns.

\section{REFERENCES}

[1] Kayhan Z, Aldemir D, Mutlu H, et al. Which is responsible for the haemodynamic response due to the laryngoscopy and endotracheal intubation? Catecholamines, vasopressin or angiotensin? European Journal of Anaesthesiology 2005;22(10):780-5.
[2] Morin AM, Geldner G, Schwarz U, et al. Factors influencing pre-operative stress responses in coronary artery bypass graft patients. BMC Anaesthesiology 2004;4(1):7.

[3] Kovac AL. Controlling the hemodynamic response to laryngoscopy and endotracheal intubation. J Clin Anaesth 1996;8(1):63-79.

[4] Prys-Roberts C, Greene LT, Meloche R, et al. Studies of anaesthesia in relation to hypertension. II. Haemodynamic consequences of induction and endotracheal intubation. Br J Anaesth 1971;43(6):53147.

[5] Dalton B, Guiney T. Myocardial ischaemia from tachycardia and hypertension in coronary heart disease-Patients undergoing anaesthesia. Boston: Ann Mtg American Society of Anaesthesiologists 1972;20:1-2.

[6] Prys-Rroberts C. Anaesthesia and hypertension. Br J Anaesth 1984;56:711-24.

[7] Bachofen M. Supression of blood pressure increases during intubation: lidocaine or fentanyl? Anaesthetist 1988;37(3):156-61.

[8] Mikawa K, Ikegaki J, Maekawa N, et al. The effect of Diltiazem on cardiovascular response to tracheal intubation. Anaesthesia 1990;45(4):289-93.

[9] Fujii Y, Tanaka H, Saitoh Y, et al. Effects of calcium channel blockers on circulatory response to tracheal intubation in hypertensive patients: Nicardipine versus Diltiazem. Can J Anaesth 1995;42(9):785-8.

[10] Kumar S, Mishra MN, Mishra LS, et al. Comparative study of the efficacy of I.V. esmolol diltiazem and magnesium sulphate in attenuating the haemodynamic response to laryngoscopy and tracheal intubation. Ind J Anaesth 2003;47(1):41-4.

[11] Flood P, Rathmell JP, Shafer S. Stoelting's Pharmacology \& physiology in anesthetic practice. $5^{\text {th }}$ edn. Lippincott Williams \& Wilkins 2015.

[12] Guo TZ, Poree L, Golden W, et al. Antinociceptive response in nitrous oxide is mediated by supraspinal opiate and spinal alpha 2 adrenergic receptors in the rat. Anesthesiology 1996;85(4):846-52.

[13] James MFM, Beer RE, Esser JD. Intravenous magnesium sulfate inhibits catecholamine release associated with tracheal intubation. Anaesthesia and Analgesia 1989;68(6):772-6.

[14] Minogue SC, Ralph J, Lampa MJ. Laryngotracheal topicalization with lidocaine before intubation decreases the incidence of coughing on emergence from general anesthesia. Anesth Analg 2004;99(4):1253-7.

[15] Nishino T, Hiraga K, Sugimori K. Effects of i.v. lignocaine on airway reflexes elicited by irritation of the tracheal mucosa in humans anaesthetized with enflurane. Br J Anaesth 1990;64(6):682-7.

[16] Pedersen T, Eliasen K, Henriksen E. A prospective study of risk factors and cardiopulmonary complications associated with anaesthesia and surgery: risk indicators of cardiopulmonary morbidity. Acta Anaesthesiol Scand 1990;34(2):144-55. 
[17] Roy WL, Edelist G, Gilbert B. Myocardial ischemia during non-cardiac surgical procedures in patients with coronary artery disease. Anaesthesiology 1979;51(5):393-7.

[18] Thomson IR. The haemodynamic response to intubation: a perspective. Can J Anaesth 1989;36(4):367-9.

[19] Fuijii Y, Saitoh Y, Takahashi S, et al. Diltiazemlidocaine combination for the attenuation of cardiovascular responses to tracheal intubation in hypertensive patients. Can J Anaesth 1998;45(10):933-7.

[20] Stoelting RK. Blood pressure and heart rate changes during short duration laryngoscopy for tracheal intubation: influence of viscous or intravenous lidocaine. Anesth Analg 1978;57(2):197-9.

[21] Bennett PB, Woosley RL, Hondeghem LM. Competition between lidocaine and one of its metabolites, glycylxylidide, for cardiac sodium channels. Circulation 1988;78(3):692-700.

[22] Abou-Madi MN, Keszler H, Yacoub JM. Cardiovascular reactions to laryngoscopy and tracheal intubation following small and large intravenous dose of lidocaine. Can Anaesth Soc J 1977;24(1):12-9.

[23] Boas RA, Covino BG, Shahnatian A. Analgesic responses to i.v. lignocaine. $\mathrm{Br} \mathrm{J}$ Anaesth 1982;54(5):501-5.

[24] Splinter WM, Cervenko F. Haemodynamic responses to laryngoscopy and tracheal intubation in geriatric patients: effects of fentanyl, lidocaine and thiopentone. Can J Anaesth 1989;36(4):370-6.

[25] Hamill JF, Bedford RF, Weaver DC, et al. Lidocaine before endotracheal intubation: intravenous or laryngotracheal? Anesthesiology 1981;55(5):578-81.

[26] Wilson IG, Meiklejohn BH, Smith G. Intravenous lignocaine and sympathoadrenal responses to laryngoscopy and intubation. The effect of varying time of injection. Anaesthesia 1991;46(3):177-80.

[27] Tam S, Chung F, Campbell M. Intravenous lidocaine: optimal time of injection before tracheal intubation. Anesth Analg 1987;66(10):1036-8.

[28] Miller CD, Warren SJ. IV lignocaine fails to attenuate the cardiovascular response to laryngoscopy and tracheal intubation. Br J Anaesth 1990;65(2):216-9.

[29] Hasegawa J, Mitshuhata H, Matsumoto S, et al. Attenuation of cardiovascular response to laryngoscopy and tracheal intubation with bolus injection of diltiazem. Masui 1992;41(3):356-62.

[30] Dahlgren N, Messeter K. Treatment of the stress response to laryngoscopy and intubation with Fentanyl. Anaesthesia 1981;36(11):1022-6.
[31] Denlinger JK, Ellison N, Ominsky AJ. Effects of intratracheal lidocaine on circulatory responses to tracheal intubation. Anaesthesiology 1974;41(4):40912.

[32] Stoelting RK. Attenuation of blood pressure response to laryngoscopy and tracheal intubation with sodium nitroprusside. Anesth Analg 1979;58(2):116-9.

[33] Shimada K, Kawamoto A, Matsubayashi K, et al. Silent cerebrovascular disease in the elderly: correlation with ambulatory pressure. Hypertension 1990;16(6):692-9.

[34] Mohan K, Roopa ML. Attenuation of cardiovascular responses to laryngoscopy and intubation by diltiazem and lignocaine: a comparative study. IJMRHS 2013;2(3):557-63.

[35] Manjunath HG, Venkatesh GS, Prima V. Can Calcium and Sodium channel blockers attenuate hemodynamic responses to endotracheal intubation? European Journal of General Medicine 2008;5(4):198-207.

[36] King BD, Harris LC Jr, Greifenstein FE, et al. Reflex circulatory responses to direct laryngoscopy and intubation under general anaesthesia. Anaesthesiology 1951;12(5):556-66.

[37] Goel S, Sharma AD, Goyal R, et al. A Randomized double blind comparative study of intravenous diltiazem and lignocaine in attenuating haemodynamic stress during laryngoscopy and endotracheal intubation in Western Uttar Pradesh. Indian Journal of Public Health \& Research Development 2014;5(4):319-12.

[38] Singh S, Laing EF, Owiredu WKBA, et al. A study of the efficacy of cardiac antidysrhythmic drugs in attenuating haemodynamic responses to laryngoscopy and endotracheal intubation in the black population. J Anesthe Clinic Res 2013;4:326.

[39] Bukhari ST, Shah MA, Chikan GPA, et al. Double blind placebo controlled study to compare the efficacy of esmolol and diltiazem in attenuation of pressor response due to laryngoscopy and endotracheal intubation in controlled hypertensive surgical patients. International Journal of Contemporary Medical Research 2016;3(1):62-5.

[40] Gobel FL, Norstorm LA, Nelson RR, et al. The ratepressure product as an index of myocardial oxygen consumption during exercise in patients with angina pectoris. Circulation 1978;57(3):549-56.

[41] Robinson BF. Relation of heart rate and systolic blood pressure to the onset of pain in angina pectoris. Circulation 1967;35(6):1073-83. 